\title{
Neural Substrates of Attentional Bias for Smoking-Related Cues: An fMRI Study
}

\author{
Amy C Janes*,', Diego A Pizzagalli', Sarah Richardt', Blaise de B Frederick', Avram J Holmes², \\ Jessica Sousa ${ }^{3}$, Maurizio Fava ${ }^{3}$, A Eden Evins ${ }^{3,4}$ and Marc J Kaufman ${ }^{1,4}$ \\ 'Brain Imaging Center, McLean Hospital, Belmont, MA, USA; '2Department of Psychology, Harvard University, Cambridge, MA, USA; \\ ${ }^{3}$ Department of Psychiatry, Massachusetts General Hospital, Boston, MA, USA
}

\begin{abstract}
Attentional bias for drug-related stimuli, as measured by emotional Stroop (ES) tasks, is predictive of treatment outcomes for tobacco smoking and other abused drugs. Characterizing relationships between smoking-related attentional bias and brain reactivity to smoking images may help in identifying neural substrates critical to relapse vulnerability. To this end, we investigated putative relationships between interference effects in an offline smoking ES task and functional MRI ( $\mathrm{fMRI}$ ) measures of brain reactivity to smoking vs neutral images in women smokers. Positive correlations were found between attentional bias and reactivity to smoking images in brain areas involved in emotion, memory, interoception, and visual processing, including the amygdala, hippocampus, parahippocampal gyrus, insula, and occipital cortex. These findings suggest that smokers with elevated attentional biases to smoking-related stimuli may more readily shift attention away from other external stimuli and toward smoking stimuli-induced internal states and emotional memories. Such attentional shifts may contribute to increased interference by smoking cues, possibly increasing relapse vulnerability. Treatments capable of inhibiting shifts to drug cue-induced memories and internal states may lead to personalized tobacco dependence treatment for smokers with high attentional bias to smoking-related stimuli.

Neuropsychopharmacology (2010) 35, 2339-2345; doi:I0.1038/npp.2010.103; published online II August 2010
\end{abstract}

Keywords: $\mathrm{fMRI}$; smoking; smoking emotional stroop; interference; interoception; memory

\section{INTRODUCTION}

The World Health Organization recently reported that tobacco use could contribute to the deaths of one billion people in the twenty-first century (World Health Organization, 2008). Despite this sobering statistic, relapse rates remain high for smokers attempting to quit (Garvey et al, 1992; Fiore et al, 1994; Etter and Stapleton, 2006). During a smoking cessation attempt, most relapse episodes occur following exposure to smoking cues (Shiffman et al, 1996; Ferguson and Shiffman, 2009). Yet, the link between relapse and smoking cue-induced craving is inconsistent (Perkins, 2009). This inconsistency may be due to individual variability in smoking cue reactivity and to limitations in instruments typically used to measure cue reactivity and craving. For example, self-reported measures of smoking cue reactivity and subsequent coping mechanisms have not identified smokers vulnerable to relapse (Shiffman et al, 1996). Conversely, certain laboratory-based approaches, such

\footnotetext{
*Correspondence: Dr AC Janes, Brain Imaging Center, McLean Hospital, I I 5 Mill Street, Belmont, MA 02478, USA, Tel: + 617855 3244, Fax: + 617855 2770, E-mail: ajanes@mclean.harvard.edu

${ }^{4}$ These authors contributed equally to this work.

Received 31 January 2010; revised 26 May 2010; accepted I5 June 2010
}

as Stroop tasks involving smoking-related cues - hereafter referred to as smoking emotional Stroop (SES) task - have shown promise for predicting smoking cessation outcomes when administered during or before quit attempts (Waters et al, 2003; Janes et al, 2010). This suggests that the SES may be useful for phenotyping smokers with varying degrees of relapse vulnerability. The goal of this study was to explore links between performance on the SES and brain reactivity to smoking cues, which may further our understanding of neural substrates involved in relapse vulnerability.

The SES is a variant of the traditional Stroop interference task that requires subjects to name the font color of smoking-related or neutral words as quickly and accurately as possible while ignoring word meaning. Smokers with attentional bias for smoking words are defined as those taking longer to name font colors of smoking-related $v s$ neutral words (Gross et al, 1993; Waters et al, 2003), likely due to interference stemming from the semantic content of smoking words (Gross et al, 1993). A recent study from our group documented that smokers with greater smokingrelated word attentional biases were more vulnerable to relapse during treatment with a combination of nicotine replacement therapy (NRT) and cognitive behavioral therapy (Janes et al, 2010).

Functional MRI (fMRI) studies have identified a number of brain regions that are reactive to smoking cues 
(Due et al, 2002; Franklin et al, 2007; McClernon et al, 2008; Janes et al, 2009). Although our recent study documented links between heightened smoking-related attentional biases and increased insula reactivity to smoking images in smokers who lapse after establishing abstinence (Janes et al, 2010), it remains unknown whether general brain reactivity patterns to smoking cues differ as a function of attentional bias to smoking-related words. Accordingly, in this study, we correlated behavioral performance on offline SES task with fMRI brain reactivity patterns to smokingrelated vs neutral images.

Smokers with increased attentional bias may have disrupted activation in cognitive control regions when performing the SES task. In this regard, brain regions involved in cognitive control, attention, and performance monitoring such as the anterior cingulate and prefrontal cortex have been implicated in the performance of the traditional Stroop task and its variants (MacDonald et al, 2000; Mitchell, 2005; Bush and Shin, 2006; Holmes and Pizzagalli, 2008). However, in this study we focused on putative links between SES interference effects and brain reactivity to smoking cues rather than on brain reactivity during SES task performance per se. It can be noted that individuals with an attentional bias toward emotionally salient words show increased fMRI activity in brain regions involved in emotional processing such as the amygdala and insula (Britton et al, 2009; Freed et al, 2009). Such enhanced emotional reactivity to salient cues may act as a distracter. Therefore, we hypothesized that attentional bias to smoking words would be positively correlated with fMRI reactivity in brain regions mediating enhanced attention toward smoking images, including regions involved in emotion and recall of smoking-related memories.

\section{METHODS}

A total of 28 women aged $44.3 \pm 10.2$ years (mean \pm SD) were referred from a smoking cessation and relapse prevention clinical trial at Massachusetts General Hospital (MGH, NCT00218465) and enrolled in this study at McLean Hospital. Subjects included 21 individuals investigated in a recent fMRI study from our laboratory (Janes et al, 2010). The methods outlined here are similar to those reported in that study. All study procedures took place while participants were active smokers, before smoking cessation treatment began. Participants met DSM-IV criteria for current nicotine dependence, reported smoking at least 10 cigarettes per day in the last 6 months, and had a minimum expired air carbon monoxide $(\mathrm{CO})>10$ p.p.m. Exclusion criteria included an unstable medical illness, pregnancy, recent drug/alcohol use (QuickTox 11 Panel Drug Test Card, Branan Medical Corporation, Irvine, California; AlcoSensor IV, Intoximeters, St Louis, MO), lifetime diagnosis of organic mental disorder, schizophrenia, schizoaffective disorder, bipolar disorder, delusional disorder, psychotic disorder not elsewhere classified, a history of alcohol abuse, a diagnosis of major depressive disorder in the past 6 months, or no response to an adequate course of NRT in the past month. All psychiatric disorders were identified using the structured clinical interview DSM-IV (SCID). Men were not enrolled, as the parent clinical trial involved an investigational medication approved by the FDA only for women. The McLean Hospital and MGH Institutional Review Boards approved this study, and subjects provided written informed consent and were compensated.

\section{SES Task}

Subjects performed in a separate behavioral session a computerized SES task, which was based on work by Waters et al (2003). Smoking behavior was not restricted until shortly before the task. The SES task included neutral and smoking-related words displayed in red, green, or blue fonts, and words were matched for length and frequency of use in the English language. Participants were asked to identify the font color as quickly and accurately as possible, using a button press, while ignoring word meaning. After a 96-trial practice block of letter strings, four experimental blocks each containing 33 trials (words) were run in the following order: neutral, smoking, smoking, neutral. Blocks were separated by 5-s breaks. In each block, each word ( $n=11)$ was repeated three times (once for each color). To replicate previous studies and avoid smoking-related word carryover effects, analyses were restricted to the first two blocks (Waters et al, 2003; Janes et al, 2010).

Each trial began with presentation of a 500-ms fixation cross, followed by word presentation until a response was made, followed by a 500-ms inter-trial interval. The word disappeared and a new trial started after a 500-ms interval if no response occurred within $3 \mathrm{~s}$, a brief $(500 \mathrm{~ms})$ tone was presented after incorrect/missing responses. Eprime software (Psychology Software Tools, Pittsburgh, PA) was used to present stimuli and to record participant responses in the form of reaction times (RTs) and accuracies. To minimize outlier response effects, trials with $150 \mathrm{~ms}>\mathrm{RT}>1500 \mathrm{~ms}$ were excluded as were trials with natural log-transformed RT falling outside the range of mean $\pm 3 S D$ (calculated after the removal of trials with $150 \mathrm{~ms}>\mathrm{RT}>1500 \mathrm{~ms}$ ). Following established procedures (eg, Williams et al, 1996), an attentional bias score was computed as $\mathrm{RT}_{\text {Smoking }}-\mathrm{RT}_{\text {Neutral }}$, with higher values indicating increased interference effects associated with smoking-related words.

\section{Subject Demographics}

Smoking behavior was defined by pack-years of tobacco smoking, expiratory CO levels (Bedfont Micro IV Smokerlyzer, Bedfont Scientific, Kent, UK), the number of cigarettes smoked the morning before the fMRI scan, and by administering the Fagerstrom Test for Nicotine Dependence (FTND; Fagerstrom, 1978). The Hamilton Rating Scale for Depression (HAMD, Hamilton, 1967) was used to assess depressive symptoms. In addition, subjects were given the Questionnaire of Smoking Urges (QSUs; Cox et al, 2001) at the screening visit. Subject demographics are presented as mean $\pm \mathrm{SD}$.

A brief clinical assessment was conducted immediately before fMRI scans, including vital sign measurements, urine testing to exclude pregnancy (QuPID One-Step Pregnancy Tests, Stanbio Laboratory, Boerne, TX) and to exclude recent illicit drug use (QuickTox 11 Panel Drug Test Card, Branan Medical Corporation). In addition, expired air CO (Bedfont Micro IV Smokerlyzer, Bedfont Scientific) and 
breathalyzer tests (Alco-Sensor IV, Intoximeters, St Louis MO) were conducted to detect recent smoking and alcohol consumption. No subjects tested positive for recent alcohol or drug use.

\section{Scanning Procedures}

We used an fMRI paradigm described previously (Janes et al, 2009; Janes et al, 2010) and modeled after Due et al (2002) during which subjects viewed color photographs of smoking-related or neutral images created by Gilbert and Rabinovich (1999). Smoking-related images included photos of people smoking, hands holding cigarettes, or cigarettes alone. Neutral images were matched for general content (faces, hands, etc.), but were devoid of smoking cues. Target images (animals) were included to ensure that subjects attended to picture sets but were excluded from data analyses. When target images appeared, subjects were instructed to respond by pressing a button on a button box. In all, 42 smoking-related images, 40 neutral images, and 8 target images were presented to each subject in a pseudorandom order, with no more than two of the same stimulus type appearing consecutively. Each image was displayed for $4 \mathrm{~s}$ and a fixation cross was shown for $14 \mathrm{~s}$ between each image presentation. Smoking was not restricted until shortly before imaging.

fMRI was performed using a Siemens Trio 3 Tesla scanner (Erlangen, Germany) with a circularly polarized head coil. Structural images were acquired using a multiplanar rapidly acquired gradient-echo sequence $(\mathrm{TR}=2.1 \mathrm{~s}, \mathrm{TE}=2.7 \mathrm{~ms}$, slices $=128$, matrix $=256 \times 256$, flip angle $=12$, resolution $=1 \times 1 \times 1.33 \mathrm{~mm}$ ). Functional images were acquired in the axial plane using gradient-echo echo-planar imaging $(\mathrm{TR}=2 \mathrm{~s}, \mathrm{TE}=30 \mathrm{~ms}$, matrix $=64 \times 64$, field of view $=224$, flip angle $=75$, slices $=30$, resolution $=3.5$ isotropic with a gap of 0 ).

\section{Imaging Analysis}

Image analysis was conducted using Brain Voyager QX 1.10.4 (Brain Innovation, Maastricht, the Netherlands), following procedures previously described (Janes et al, 2009; Janes et al, 2010). Images were slice-time corrected, motion corrected, spatially smoothed using a Gaussian kernel of $6 \mathrm{~mm}$, spatially normalized into Talairach space, and the voxel size was resampled to $3 \times 3 \times 3 \mathrm{~mm}$. To further reduce the effects of motion-related variability, an in-house program was used to model out data time points exhibiting absolute or relative motion exceeding threshold values (set to $1.75 \mathrm{~mm}$, equivalent to half the total voxel size).

Voxels exhibiting heightened fMRI reactivity to smoking $v s$ neutral images were identified using a general linear model containing the three image predictors (smoking images, neutral images, and target images) and the motion confound predictors. The square waves defined by image onset and offset were convolved with the $2-\gamma$ hemodynamic response function. The relationship between brain reactivity to smoking $>$ neutral images and attentional bias $\left(\mathrm{RT}_{\text {Smoking }}-\mathrm{RT}_{\text {Neutral }}\right)$ was assessed using a random effects analysis of covariates (ANCOVA), where SES score was the covariate. A Monte Carlo simulation (Slotnick et al, 2003) determined the cluster extent necessary to correct for multiple comparisons. This method has been described in our previous work (Janes et al, 2009; Janes et al, 2010). Ten thousand permutations determined that a cluster of twentysix $3 \times 3 \times 3$ voxels equaling $702 \mathrm{~mm}^{3}$ was needed to correct an individual voxel type 1 error of $p<0.05$ to a cluster-level corrected threshold of $p<0.05$.

\section{RESULTS}

\section{ES Task and Demographics}

On an average, subjects had an attentional bias score of $23.3 \pm 67.5 \mathrm{~ms}$; critically, the range was wide (from 164 to $-57.5 \mathrm{~ms}$ ), corroborating the use of a correlational approach. HAMD scores were in the normal range $2.4 \pm 2.4$ indicating no current depressive symptoms. FTND scores were 5.6 \pm 2.2 , indicating nicotine dependence. Subjects smoked $4.3 \pm 2$ cigarettes before the scanning session. Smoking behavior was confirmed with CO levels averaging $19.1 \pm 8.0$ p.p.m. In all, 26 of the 28 subjects who completed the QSU had a total score of $27.0 \pm 8.8$.

\section{fMRI Cue Reactivity}

Correlations between attentional bias and fMRI reactivity. A positive correlation was found between attentional bias to smoking words and increased brain reactivity to smoking $>$ neutral images in the bilateral insula (BA 13), bilateral parahippocampal gyrus (BA 35, 36), left hippocampus, left amygdala, and left visual processing areas (BA 18, 19). A negative correlation was found between attentional bias and brain reactivity to smoking $>$ neutral images in the precuneus (BA 7$)\left(r_{\min }>0.37, p_{\text {corrected }}<0.05\right.$, Table 1, Figure 1; see Supplementary Materials for scatter plots for each cluster).

\section{DISCUSSION}

The main finding emerging from this study is that attentional bias toward smoking-related words was positively correlated with greater brain reactivity to smoking $v s$ neutral images in brain regions involved in memory, emotion, interoception, and visual spatial processing. The correlations may indicate that regions supporting these processes are part of the neural substrate of smokingrelated attentional bias.

In line with our a priori hypothesis, attentional bias was positively correlated with insula and amygdala reactivity to smoking images. Potentiated insula activation is consistent with the notion that smoking images may trigger interoceptive awareness in smokers with a high attentional bias. Not only is the insula involved in interoceptive awareness (Craig, 2002; Craig, 2009), but its activity has also been associated with cigarette craving (Brody et al, 2002), and the insula is thought to be critical for the maintenance of smoking behavior (Naqvi et al, 2007; Janes et al, 2010). The amygdala is involved in stimulus-reward associations (Kentridge et al, 1991), including the acquisition and expression of conditioned drug-cue associations (See et al, 2003). Thus, the amygdala and insula may have important 
Table I Brain Reactivity to Smoking vs Neutral Images Correlated with Smoking Emotional Stroop Task Performance

\begin{tabular}{|c|c|c|c|c|c|c|}
\hline Brain area & Brodmann area & $x$ & y & $\mathbf{z}$ & Volume $\left(\mathrm{mm}^{3}\right)$ & $r$ \\
\hline \multicolumn{7}{|l|}{ Positive correlation } \\
\hline Insula & 13 & 35 & 3.5 & -10 & 934 & 0.56 \\
\hline Parahippocampal gyrus & 35,36 & 22 & -35 & -14 & 1088 & 0.64 \\
\hline Amygdala, hippocampus, parahippocampal gyrus, insula & 13,36 & -28 & 0 & -14 & 1255 & 0.61 \\
\hline Middle occipital gyrus, fusiform gyrus & 18,19 & -35 & -86 & -8 & 1300 & 0.58 \\
\hline Precuneus & 7 & -3 & -35 & 43 & 910 & -0.55 \\
\hline Precuneus & 7 & -8 & -49 & 52 & 1155 & -0.58 \\
\hline
\end{tabular}

Brain area and Brodmann area refer to the location of each cluster of contiguous voxels. Talairach and Tournoux coordinates (Talairach and Tournoux, 1988) refer to the center of mass for each cluster of continuous voxels. The volume refers to the total volume $\left(\mathrm{mm}^{3}\right)$ per cluster. The $r$-values refer to the maximum correlation statistic in each cluster.

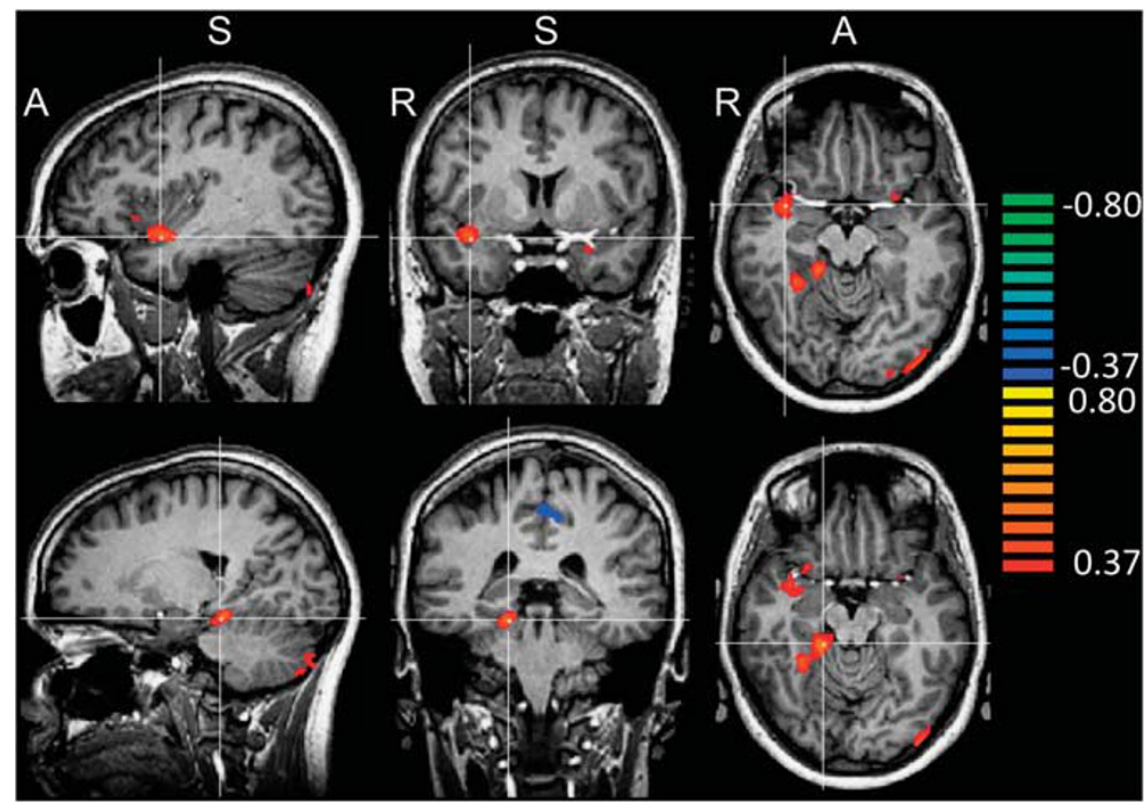

Figure I Whole-brain analysis correlating brain reactivity to smoking vs neutral images with SES task performance. A positive correlation was found between brain reactivity and SES interference effects in the insula, amygdala, hippocampus, parahippocampal gyrus, and occipital cortex. Top panel crosshairs are located in the right insula. Talairach (Talairach and Tournoux, 1988) coordinates of the crosshairs: $x=36, y=2, y=-12$. Bottom panel crosshairs are located in the right parahippocampal gyrus $(x=17, y=-32, x-14)$. For all panels $r_{\min }=0.37, p_{\text {corrected }}<0.05$.

roles in moderating smoking behavior following exposure to smoking cues.

Both the insula and amygdala are thought to be part of a neural system responsible for the identification of emotionally salient stimuli and subsequent emotional responses (Phillips et al, 2003). The amygdala may enhance identification of emotionally salient stimuli by increasing sensory processing through reciprocal connections with the visual cortex (Amaral et al, 2003). Correlations between SES scores and increased visual cortex reactivity suggest that sensory processing of smoking stimuli may indeed be enhanced in smokers with a greater attentional bias.

The amygdala also acts as an emotional memory system that may enhance related episodic memory (for review Phelps, 2004), including the ability to mentally replay a personal experience. Recollections of such memories are modulated by the hippocampus and parahippocampal gyrus (Cabeza and Nyberg, 2000; Fortin et al, 2004; Kirwan and Stark, 2004; Manns and Eichenbaum, 2006; Ross and Slotnick, 2008). Eichenbaum et al (2007) defined recollection as 'the recovery of qualitative associations prompted by a critical cue' ( $p$ 124). In the context of this study, smoking cues may trigger smoking-related associations leading to the mental rehearsal of past smoking experiences. The correlations between attentional bias and hippocampal and parahippocampal activations suggests that smokingrelated memories may be more readily triggered by cues in those with a greater attentional bias. Correlations between SES scores and insula and amygdalar reactivity further indicate that recalled episodes might have a greater emotional component in smokers with elevated attentional biases. Such memories and attention to internal states may 
act as a distracter, thereby interfering with SES performance, which requires attention to an external stimulus (font color). Collectively, these processes might increase motivation for smoking behavior and thus contribute to increased relapse vulnerability exhibited by this group.

A negative correlation was found between smokingrelated attentional biases and precuneus reactivity to smoking vs neutral images. The precuneus is involved in target detection (Corbetta et al, 2000), suggesting that smokers with decreased attentional bias may be processing smoking images as targets. However, when exposed to smoking cues, smokers with lower attentional bias may not be engaging brain regions facilitating the motivation to smoke. McClernon et al (2008) has suggested that, when presented with smoking cues, less-dependent smokers engage brain regions involved in attention as opposed to regions involved in motivational behavior. All smokers may preferentially respond to smoking $v s$ neutral images, yet the pattern of brain activation may differ based on the degree of the attentional bias. This differential pattern may explain why smokers with a greater attentional bias are more distracted by smoking cues.

A previous SES study showed that, on an average, nonabstinent smokers are slower at naming neutral vs smoking words in comparison to $12-\mathrm{h}$ abstinent smokers (Gross et al, 1993). One explanation for this 'reverse smoking-word attentional bias' is that smokers are more familiar with smoking terms and can quickly process and disregard them when in the nonabstinent state. A similar argument could be made when comparing nonabstinent smokers with different levels of attentional bias. Smokers with lower attentional bias may quickly process smoking 'targets', whereas those with higher attentional bias may experience interference from smoking-related memories, emotion, and interoception, leading to the motivation to smoke.

This study was limited to women who, in comparison to men, are especially vulnerable to smoking cues (Perkins et al, 2001; Field and Duka, 2004). Attentional bias correlated with brain regions involved in emotion, memory, and interoception, suggesting that these processes may enhance smoking attentional bias. Such processes may be particularly important in moderating relapse vulnerability in women as they are better at recalling autobiographical events and when doing so use more emotional terms and describe more internal states (for review see Andreano and Cahill, 2009). In comparison to men, women also show greater left amygdala (Cahill et al, 2001) and insular reactivity when processing emotional memories (Piefke et al, 2005). In addition, women may be more vulnerable to cue reactivity than men because of this sex difference in emotional memory processing. The possibility exists that men and women engage different neural networks when responding to smoking stimuli, although further research is needed to test this hypothesis.

A recent study has indicated that D-cycloserine treatment in combination with cue-exposure therapy attenuates smoking cue reactivity (Santa Ana et al, 2009). It may be useful to determine whether this combined treatment would reduce the interfering effects of smoking-related words during SES performance, as well as reduce relapse vulnerability in smokers identified as having attentional bias for smoking-related words. Attentional bias not only predicts treatment outcomes for tobacco smokers but also for other drugs of abuse (Cox et al, 2002; Waters et al, 2003; Carpenter et al, 2006; Marissen et al, 2006). Accordingly, the current findings may extend to individuals dependent on a range of addictive substances.

\section{Limitations}

This study was limited to women and so it remains unknown whether brain fMRI reactivity to smoking images differs in male smokers with different degrees of attentional bias. Further, women's hormonal status was not measured and should be included as a variable in future studies. In addition, some participants withdrew from the clinical trial before randomization to the investigational medication. Therefore, outcomes in all subjects were not available, and we are unable to relate SES performance and brain reactivity to smoking cessation outcomes. However, it seems reasonable to infer that a relationship between smoking-word attentional bias and treatment outcome may exist based on previous work establishing a link between attentional bias for smoking-related words and relapse vulnerability (Waters et al, 2003; Janes et al, 2010). Finally, subjective craving was not assessed at the time of the SES task or the fMRI scan. However, an association between insula reactivity to smoking cues and craving has been reported (Brody et al, 2002), suggesting that there may be a connection between these types of measures. To address these limitations, we plan future studies that will include larger cohorts of women and men, conducted in the context of a clinical trial quantifying smoking cessation treatment outcomes. Notwithstanding these limitations, this study suggests that there is a neural basis for smoking cue reactivity differences between smokers with different magnitudes of attentional bias for smoking-related words. This neural difference could explain performance differences on the SES task and could be related to relapse vulnerability. Research into smoking cessation and relapseprevention treatments targeted at disrupting smoking cueinduced triggering of associated memories and interoceptive states may lead to more successful treatments for smokers and other drug-dependent individuals with attentional biases for drug-related stimuli.

\section{DISCLOSURE}

DAP: research support from ANT North America Inc. (Advanced Neuro Technology), consulting fees from ANT North America Inc. (Advanced Neuro Technology), and AstraZeneca for projects unrelated to the current study, and honoraria from AstraZeneca. AEE: research product support from Pfizer, and Speaker Honoraria from Reed Medical Education. MF: research support from Abbott Laboratories, Alkermes, Aspect Medical Systems, AstraZeneca, BioResearch, BrainCells, Inc., Bristol-Myers Squibb Company, Cephalon, Clinical Trial Solutions, LLC, Eli Lilly \& Company, Forest Pharmaceuticals Inc., Ganeden, GlaxoSmithKline, J \& J Pharmaceuticals, Lichtwer Pharma GmbH, Lorex Pharmaceuticals, NARSAD, NCCAM, NIDA, NIMH, Novartis, Organon Inc., PamLab, LLC, Pfizer Inc., 
Pharmavite, Roche, Sanofi-Aventis, Shire, Solvay Pharmaceuticals, Inc., Synthelabo, and Wyeth-Ayerst Laboratories.

Advisory/consulting: Abbott Laboratories, Amarin, Aspect Medical Systems, AstraZeneca, Auspex Pharmaceuticals, Bayer AG, Best Practice Project Management, Inc, BioMarin Pharmaceuticals, Inc., Biovail Pharmaceuticals, Inc., BrainCells, Inc, Bristol-Myers Squibb Company, Cephalon, Clinical Trials Solutions,LLC, CNS Response, Compellis, Cypress Pharmaceuticals, Dov Pharmaceuticals, Eisai, Inc., Eli Lilly \& Company, EPIX Pharmaceuticals, Euthymics Bioscience, Inc., Fabre-Kramer, Pharmaceuticals, Inc., Forest Pharmaceuticals Inc., GlaxoSmithKline, Grunenthal GmBH, Janssen Pharmaceutica, Jazz Pharmaceuticals, J \& J Pharmaceuticals, Knoll Pharmaceutical Company, Labopharm, Lorex Pharmaceuticals, Lundbeck, MedAvante Inc., Merck, Methylation Sciences, Neuronetics, Novartis, Nutrition 21, Organon Inc., PamLab, LLC, Pfizer Inc., PharmaStar, Pharmavite, Precision Human Biolaboratory, PsychoGenics, Psylin Neurosciences, Inc., Ridge Diagnostics, Inc., Roche, Sanofi-Aventis, Sepracor, Schering-Plough, Solvay Pharmaceuticals, Inc., Somaxon, Somerset Pharmaceuticals, Synthelabo, Takeda, Tetragenex, TransForm Pharmaceuticals, Inc., Transcept Pharmaceuticals, Vanda Pharmaceuticals Inc., and Wyeth-Ayerst Laboratories. Speaking/publishing: Adamed, Co., Advanced Meeting Partners, American Psychiatric Association, American Society of Clinical Psychopharmacology, AstraZeneca, Belvoir, Boehringer-Ingelheim, Bristol-Myers Squibb Company, Cephalon, Eli Lilly \& Company, Forest Pharmaceuticals Inc., GlaxoSmithKline, Imedex, Novartis, Organon Inc., Pfizer Inc, PharmaStar, MGH Psychiatry Academy/ Primedia, MGH Psychiatry Academy/Reed-Elsevier, UBC, and Wyeth-Ayerst Laboratories.

Equity holdings: Compellis

Royalty/patent, other income: patent applications for SPCD and for a combination of azapirones and bupropion in MDD, copyright royalties for the MGH CPFQ, SFI, ATRQ, DESS, and SAFER

MJK: research support from GSK, Organon, Varian Inc., Advisory/consulting: Amgen, Novartis.

ACJ, BBF, SR, AJH, and JS declare no conflict of interest.

\section{REFERENCES}

Amaral DG, Behniea H, Kelly JL (2003). Topographic organization of projections from the amygdala to the visual cortex in the macaque monkey. Neuroscience 118: 1099-1120.

Andreano JM, Cahill L (2009). Sex influences on the neurobiology of learning and memory. Learn Mem 16: 248-266.

Britton JC, Gold AL, Deckersbach T, Rauch SL (2009). Functional MRI study of specific animal phobia using an event-related emotional counting stroop paradigm. Depress Anxiety 26: 796-805.

Brody AL, Mandelkern MA, London ED, Childress AR, Lee G, Bota $\mathrm{R}$ et al (2002). Brain metabolic changes during cigarette craving. Arch Gen Psychiatry 59: 1162-1172.

Bush G, Shin LM (2006). The multi-source interference task: an fMRI task that reliably activates the cingulo-frontal-parietal cognitive/attention network. Nat Protoc 1: 308-313.

Cabeza R, Nyberg L (2000). Imaging cognition II: an empirical review of 275 PET and fMRI studies. J Cogn Neurosci 12: 1-47.

Cahill L, Haier RJ, White NS, Fallon J, Kilpatrick L, Lawrence C et al (2001). Sex-related difference in amygdala activity during emotionally influenced memory storage. Neurobiol Learn Mem 75: 1-9.

Carpenter KM, Schreiber E, Church S, McDowell D (2006). Drug Stroop performance: relationships with primary substance of use and treatment outcome in a drug-dependent outpatient sample. Addict Behav 31: 174-181.

Corbetta M, Kincade JM, Ollinger JM, McAvoy MP, Shulman GL (2000). Voluntary orienting is dissociated from target detection in human posterior parietal cortex. Nat Neurosci 3: 292-297.

Cox LS, Tiffany ST, Christen AG (2001). Evaluation of the brief questionnaire of smoking urges (QSU-brief) in laboratory and clinical settings. Nicotine Tob Res 3: 7-16.

Cox WM, Hogan LM, Kristian MR, Race JH (2002). Alcohol attentional bias as a predictor of alcohol abusers' treatment outcome. Drug Alcohol Depend 68: 237-243.

Craig AD (2002). How do you feel? Interoception: the sense of the physiological condition of the body. Nat Rev Neurosci 3: 655-666.

Craig ADB (2009). How do you feel-now? The anterior insula and human awareness. Nat Rev Neurosci 10: 59.

Due DL, Huettel SA, Hall WG, Rubin DC (2002). Activation in mesolimbic and visuospatial neural circuits elicited by smoking cues: evidence from functional magnetic resonance imaging. Am J Psychiatry 159: 954-960.

Eichenbaum H, Yonelinas AP, Ranganath C (2007). The medial temporal lobe and recognition memory. Annu Rev Neurosci 30: 123-152.

Etter J-F, Stapleton JA (2006). Nicotine replacement therapy for longterm smoking cessation: a meta-analysis. Tob Control 15: 280-285.

Fagerstrom KO (1978). Measuring degree of physical dependence to tobacco smoking with reference to individualization of treatment. Addict Behav 3: 235-241.

Ferguson SG, Shiffman S (2009). The relevance and treatment of cue-induced cravings in tobacco dependence. J Subst Abuse Treat 36: 235-243.

Field M, Duka T (2004). Cue reactivity in smokers: the effects of perceived cigarette availability and gender. Pharmacol Biochem Behav 78: 647-652.

Fiore MC, Smith SS, Jorenby DE, Baker TB (1994). The effectiveness of the nicotine patch for smoking cessation. A meta-analysis. JAMA 271: 1940-1947.

Fortin NJ, Wright SP, Eichenbaum H (2004). Recollection-like memory retrieval in rats is dependent on the hippocampus. Nature 431: 188-191.

Franklin TR, Wang Z, Wang J, Sciortino N, Harper D, Li Y et al (2007). Limbic activation to cigarette smoking cues independent of nicotine withdrawal: a perfusion fMRI study. Neuropsychopharmacology 32: 2301-2309.

Freed PJ, Yanagihara TK, Hirsch J, Mann JJ (2009). Neural mechanisms of grief regulation. Biol Psychiatry 66: 33-40.

Garvey AJ, Bliss RE, Hitchcock JL, Heinold JW, Rosner B (1992). Predictors of smoking relapse among self-quitters: a report from the Normative Aging Study. Addict Behav 17: 367-377.

Gilbert DG, Rabinovich NE (1999). International Smoking Image Series (with Neutral Counterparts). version 1.2. Integrative Neuroscience Laboratory, Department of Psychology, Southern Illinois University.

Gross TM, Jarvik ME, Rosenblatt MR (1993). Nicotine abstinence produces content-specific Stroop interference. Psychopharmacology 110: 333-336.

Hamilton M (1967). Development of a rating scale for primary depressive illness. Br J Soc Clin Psychol 6: 278-296.

Holmes AJ, Pizzagalli DA (2008). Spatiotemporal dynamics of error processing dysfunctions in major depressive disorder. Arch Gen Psychiatry 65: 179-188.

Janes AC, Frederick BD, Richardt S, Burbridge C, Merlo-Pich E, Renshaw PF et al (2009). Brain fMRI reactivity to smokingrelated images before and during extended smoking abstinence. Exp Clin Psychopharmacol 17: 365-373. 
Janes AC, Pizzagalli DA, Richardt S, Frederick BD, Chuzi S, Pachas $G$ et al (2010). Brain reactivity to smoking cues prior to smoking cessation predicts ability to maintain tobacco abstinence. Biol Psychiatry 67: 722-729.

Kentridge RW, Shaw C, Aggleton JP (1991). Amygdaloid lesions and stimulus-reward associations in the rat. Behav Brain Res 42: $57-66$.

Kirwan CB, Stark CEL (2004). Medial temporal lobe activation during encoding and retrieval of novel face-name pairs. Hippocampus 14: 919-930.

MacDonald AW, Cohen JD, Stenger VA, Carter CS (2000). Dissociating the role of the dorsolateral prefrontal and anterior cingulate cortex in cognitive control. Science 288: 1835-1838.

Manns JR, Eichenbaum H (2006). Evolution of declarative memory. Hippocampus 16: 795-808.

Marissen MAE, Franken IHA, Waters AJ, Blanken P, van den Brink W, Hendriks VM (2006). Attentional bias predicts heroin relapse following treatment. Addiction 101: 1306-1312.

McClernon F, Kozink RV, Rose JE (2008). Individual differences in nicotine dependence, withdrawal symptoms, and sex predict transient fMRI-BOLD responses to smoking cues. Neuropsychopharmacology 33: 2148-2157.

Mitchell RLC (2005). The BOLD response during Stroop task-like inhibition paradigms: effects of task difficulty and task-relevant modality. Brain Cogn 59: 23-37.

Naqvi NH, Rudrauf D, Damasio H, Bechara A (2007). Damage to the insula disrupts addiction to cigarette smoking. Science 315: 531-534.

Perkins K (2009). Does smoking cue-induced craving tell us anything important about nicotine dependence? Addiction 104: 1610-1616.

Perkins KA, Gerlach D, Vender J, Grobe J, Meeker J, Hutchinson S (2001). Sex differences in the subjective and reinforcing effects of visual and olfactory cigarette smoke stimuli. Nicotine Tob Res 3: $141-150$
Phelps EA (2004). Human emotion and memory: interactions of the amygdala and hippocampal complex. Curr Opin Neurobiol 14: 198-202.

Phillips ML, Drevets WC, Rauch SL, Lane R (2003). Neurobiology of emotion perception I: the neural basis of normal emotion perception. Biol Psychiatry 54: 504-514.

Piefke M, Weiss PH, Markowitsch HJ, Fink GR (2005). Gender differences in the functional neuroanatomy of emotional episodic autobiographical memory. Hum Brain Mapp 24: 313-324.

Ross RS, Slotnick SD (2008). The hippocampus is preferentially associated with memory for spatial context. J Cogn Neurosci 20: 432-446.

Santa Ana EJ, Rounsaville BJ, Frankforter TL, Nich C, Babuscio T, Poling $\mathrm{J}$ et al (2009). D-cycloserine attenuates reactivity to smoking cues in nicotine dependent smokers: a pilot investigation. Drug Alcohol Depend 104: 220-227.

See RE, Fuch RA, Ledford CC, McLaughlin J (2003). Drug addiction, relapse, and the amygdala. Ann NY Acad Sci 985: 294-307.

Shiffman S, Paty JA, Gnys M, Kassel JA, Hickcox M (1996). First lapses to smoking: within-subjects analysis of real-time reports. J Consult Clin Psychol 64: 366-379.

Slotnick SD, Moo LR, Segal JB, Hart J (2003). Distinct prefrontal cortex activity associated with item memory and source memory for visual shapes. Cogn Brain Res 17: 75-82.

Talairach J, Tournoux P (1988). Co-Planar Stereotaxic Atlas of the Human Brain: 3-Dimensional Proportional System: An Approach to Cerebral Imaging. Thieme Medical Publishers: New York.

Waters AJ, Shiffman S, Sayette MA, Paty JA, Gwaltney CJ, Balabanis $\mathrm{MH}$ (2003). Attentional bias predicts outcome in smoking cessation. Health psychology: Official Journal of the Division of Health Psychology, American Psychological Association 22: 378-387.

Williams JM, Mathews A, MacLeod C (1996). The emotional Stroop task and psychopathology. Psychol Bull 120: 3-24.

World Health Organization (2008). WHO Report on the Global Tobacco Epidemic, 2008.

Supplementary Information accompanies the paper on the Neuropsychopharmacology website (http://www.nature.com/npp) 